\title{
Dysregulation of mTOR Signaling in Fragile X Syndrome
}

\author{
Ali Sharma, ${ }^{1}$ Charles A. Hoeffer, ${ }^{4}$ Yukihiro Takayasu, ${ }^{1}$ Takahiro Miyawaki, ${ }^{1}$ Sean M. McBride, $, 2,3 *$ Eric Klann, ${ }^{4 \star}$ \\ and R. Suzanne Zukin ${ }^{1}$ \\ ${ }^{1}$ Dominick P. Purpura Department of Neuroscience, ${ }^{2}$ Program in Molecular Cardiology, Department of Medicine, and ${ }^{3}$ Department of Molecular Pharmacology, \\ Albert Einstein College of Medicine, New York, New York 10461, and ${ }^{4}$ Center for Neural Science, New York University, New York, New York 10003
}

Fragile $\mathrm{X}$ syndrome, the most common form of inherited mental retardation and leading genetic cause of autism, is caused by transcriptional silencing of the Fmr1 gene. The fragile X mental retardation protein (FMRP), the gene product of $F m r 1$, is an RNA binding protein that negatively regulates translation in neurons. The Fmrl knock-out mouse, a model of fragile $\mathrm{X}$ syndrome, exhibits cognitive deficits and exaggerated metabotropic glutamate receptor (mGluR)-dependent long-term depression at CA1 synapses. However, the molecular mechanisms that link loss of function of FMRP to aberrant synaptic plasticity remain unclear. The mammalian target of rapamycin (mTOR) signaling cascade controls initiation of cap-dependent translation and is under control of mGluRs. Here we show that mTOR phosphorylation and activity are elevated in hippocampus of juvenile $F m r l$ knock-out mice by four functional readouts: (1) association of mTOR with regulatory associated protein of mTOR; (2) mTOR kinase activity; (3) phosphorylation of mTOR downstream targets S6 kinase and 4E-binding protein; and (4) formation of eukaryotic initiation factor complex $4 \mathrm{~F}$, a critical first step in cap-dependent translation. Consistent with this, mGluR long-term depression at CA1 synapses of FMRP-deficient mice is exaggerated and rapamycin insensitive. We further show that the p110 subunit of the upstream kinase phosphatidylinositol 3-kinase (PI3K) and its upstream activator PI3K enhancer PIKE, predicted targets of FMRP, are upregulated in knock-out mice. Elevated mTOR signaling may provide a functional link between overactivation of group I mGluRs and aberrant synaptic plasticity in the fragile X mouse, mechanisms relevant to impaired cognition in fragile $\mathrm{X}$ syndrome.

\section{Introduction}

Fragile $\mathrm{X}$ syndrome is an inherited form of mental retardation caused by loss-of-function mutations in the RNA binding protein fragile X mental retardation protein (FMRP). Patients with fragile X syndrome exhibit a wide range of neurological deficits, including cognitive impairment, seizures, emotional lability, sleep disorders, attentional deficits, and autism (Warren and Sherman, 2001; Hagerman and Hagerman, 2002; Jin and Warren, 2003; Jacquemont et al., 2007; Penagarikano et al., 2007; Ronesi and Huber, 2008). In humans, fragile X syndrome results from expansion of a CGG repeat sequence in the $5^{\prime}$ untranslated region and silencing of the FMR1 gene (Feng et al., 1995; Garber et al., 2006). FMRP, the gene product of FMR1, controls translational efficiency of dendritic mRNAs in response to stimulation of metabotropic glutamate receptors (mGluRs) (Banko et al., 2006; Ronesi and Huber, 2008).

\footnotetext{
Received July 30, 2009; revised Nov. 12, 2009; accepted Nov. 18, 2009.

This work was supported by generous grants from the Fragile X Syndrome Research Foundation and the National Institutes of Health Grants NS20752 (R.S.Z.), NS340007 (E.K.), and NS047384 (E.K.). We thank Adrianna LatuszekBarrantes and Evan Betzler for outstanding technical assistance. R.S.Z. is the F.M. Kirby Professor in Neural Repair and Protection.

S.M.M. and E.K. contributed equally to this work.

Correspondence should be addressed to Dr. R. Suzanne Zukin, Neuropsychopharmacology Center, Dominick P. Purpura Department of Neuroscience, Albert Einstein College of Medicine, 1300 Morris Park Avenue, Bronx, NY 10461. E-mail: suzanne.zukin@einstein.yu.edu.

Y. Takayasu's present address: Department of Neurophysiology and Otolaryngology, Gunma University Graduate School of Medicine, Gunma 371-8511, Japan.

T. Miyawaki's present address: Department of Neurosurgery, Jichi Medical University, Tochigi 329-0498, Japan. DOI:10.1523/JNEUROSCI.3696-09.2010

Copyright $\odot 2010$ the authors $\quad 0270-6474 / 10 / 300694-10 \$ 15.00 / 0$
}

mGluRs are G-protein-coupled receptors enriched at excitatory synapses throughout the brain in which they act to regulate glutamatergic neurotransmission (Nakanishi, 1994; Pin and Duvoisin, 1995; Conn and Pin, 1997). mGluRs are implicated in synaptogenesis, spine morphogenesis, and activity-dependent synaptic plasticity. Activation of group I mGluRs induces NMDA receptor-independent long-term depression (LTD) at Schaffer collateral to CA1 pyramidal cell synapses (Oliet et al., 1997; Palmer et al., 1997). Expression of mGluR-LTD is mediated by persistent internalization of AMPA receptors and in adolescent wild-type (WT) mice requires de novo protein synthesis (Huber et al., 2000; Nosyreva and Huber, 2006; Waung and Huber, 2009). The Fmrl knock-out (KO) mouse exhibits abnormalities in dendritic spine morphology (Bagni and Greenough, 2005), impaired cognition (O'Donnell and Warren, 2002), and exaggerated mGluR-LTD, which is protein synthesis independent (Huber et al., 2002; Hou et al., 2006; Nosyreva and Huber, 2006). The mechanisms that link mGluR activation to aberrant protein synthesis and mGluR-LTD in $\mathrm{KO}$ mice are, as yet, unclear.

Mammalian target of rapamycin (mTOR) is a central regulator of cell growth, proliferation, autophagy, and translation (Hay and Sonenberg, 2004; Klann and Dever, 2004; Sarbassov et al., 2005a). Components of the mTOR signaling cascade are present at synapses and influence synaptic plasticity via regulation of local protein synthesis (Tang and Schuman, 2002). mTOR is activated in dendrites by stimulation of group I mGluRs and is required for mGluR-LTD at CA1 synapses (Hou and Klann, 2004). Growing evidence indicates that dys- 
A

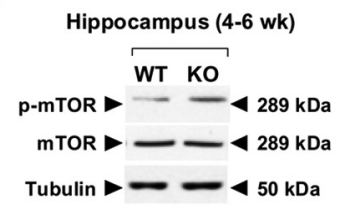

B

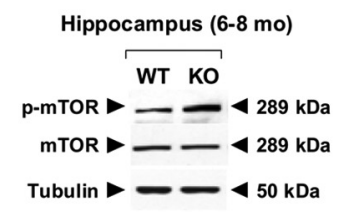

C
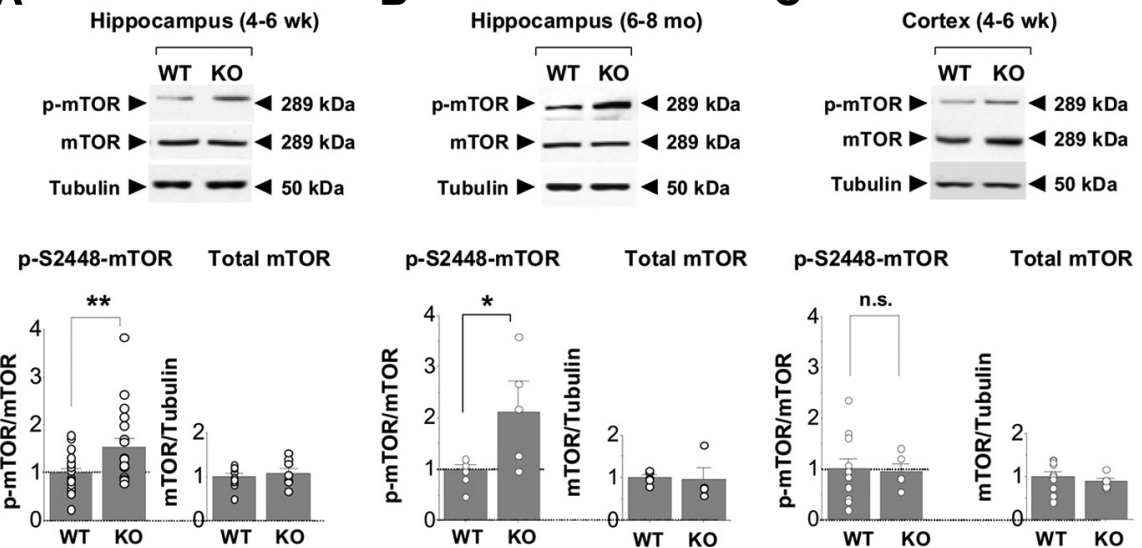

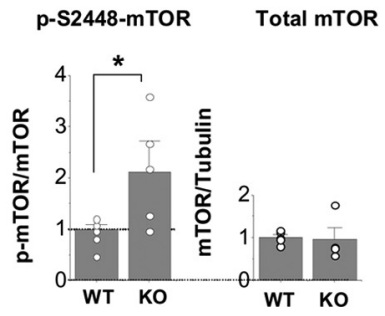

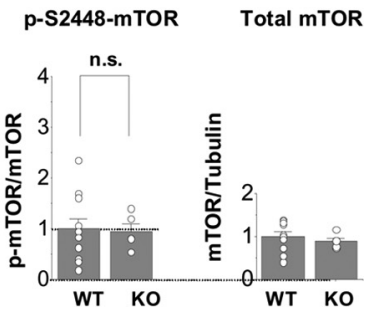

Figure 1. mTOR phosphorylation is enhanced in the hippocampus of fragile $X$ mice. Representative Western blots showing relative abundance of p-mTOR and total mTOR in lysates of hippocampus $(\boldsymbol{A})$ and cortex $(\boldsymbol{C})$ from young (4-6 weeks old) and hippocampus from old (6-8 months old; $\boldsymbol{B}$ ) mice. Fmr $1 \mathrm{KO}$ mice and aged-matched WT littermates. Western blots were probed with antibodies to p-Ser2448 -mTOR and total mTOR. Phosphorylation of mTOR is basally enhanced in the hippocampus, but not cortex, of young (increase to $53 \pm 18.9 \%$ of WT; $n=22 \mathrm{WT} ; n=18 \mathrm{K0} ; p<0.01$ ) and old (increase to $138 \pm 47.7 \%$ of WT; $n=$ 5 WT and K0; $p<0.05)$ Fmr 1 K0 animals ( $\left.{ }^{*} p<0.05 ;{ }^{* *} p<0.01\right)$.

regulation of mTOR is associated with human diseases, including cancer, diabetes, and autism (Sabatini, 2006; Dann et al., 2007).

The present study was undertaken to examine a possible role for mTOR signaling in the exaggerated mGluR-LTD exhibited by the Fmr1 KO mouse. Here we show that mTOR phosphorylation and signaling are elevated in $\mathrm{KO}$ mice, as assessed by (1) association of raptor (regulatory associated protein of $\mathrm{mTOR}$ ) with mTOR, (2) mTOR kinase activity, (3) phosphorylation of mTOR downstream targets S6K and 4E-binding protein (4E-BP), and (4) formation of eukaryotic initiation factor complex 4F (eIF4F), a first step in cap-dependent translation. Consistent with this, mGluR-LTD at CA1 synapses of Fmr1 KO mice is enhanced and rapamycin insensitive. Moreover, phosphatidylinositol 3-kinase (PI3K) and its upstream activator PI3K enhancer PIKE, putative targets of FMRP, are elevated in the hippocampus of KO mice. These findings implicate dysregulation of mTOR signaling as a critical step linking overactivation of mGluRs to exaggerated mGluR-LTD in the FMRP-deficient mouse and provide insight into cellular mechanisms underlying fragile X syndrome.

\section{Materials and Methods}

Animals. FVB; 129P-Fmr1tm1Cgr/J mice were obtained from The Jackson Laboratory and were maintained in a temperature- and lightcontrolled environment with a $14 / 10 \mathrm{~h}$ light/dark cycle and were treated in accordance with the principles and procedures of the National Institutes of Health Guide for the Care and Use of Laboratory Animals. Protocols were approved by the Institutional Animal Care and Use Committee of the Albert Einstein College of Medicine.

Immunoprecipitation. Transverse hippocampal slices $(400 \mu \mathrm{m})$ were cut from the brains of age-matched Fmr1 KO and WT mice (4-6 weeks of age) using conventional methodology. Slices were maintained at $32^{\circ} \mathrm{C}$ for at least $60 \mathrm{~min}$ in glass vials, perfused with oxygenated artificial CSF (ACSF) containing the following (in $\mathrm{mm}$ ): $125 \mathrm{NaCl}, 2.5 \mathrm{KCl}, 1.25$ $\mathrm{NaH}_{2} \mathrm{PO}_{4}, 25 \mathrm{NaHCO}_{3}, 25$ D-glucose, $2 \mathrm{CaCl}_{2}$, and $1 \mathrm{MgCl}_{2}$. Slices were harvested for protein purification after treatment with either $100 \mu \mathrm{M}$ $(R S)$-3,5-dihydroxyphenylglycine (DHPG) (Tocris Bioscience) or vehicle and a $10 \mathrm{~min}$ recovery. Tissue was homogenized in ice-cold lysis buffer containing the following: $40 \mathrm{~mm}$ HEPES, pH 7.5, $150 \mathrm{~mm} \mathrm{NaCl}, 10$ $\mathrm{mm}$ pyrophosphate, $10 \mathrm{~mm}$ glycerophosphate, $1 \mathrm{~mm}$ EDTA and $0.3 \%$ 3-[(3-cholamidopropyl)dimethylammonio]-1-propanesulfonate (CHAPS) (mTOR) or $0.5 \%$ Triton X-100 (eIF4G), protease inhibitor II, and phos- phatase inhibitor cocktail I and II (Sigma). Homogenate was incubated with either antimTOR (1:40) (Cell Signaling Technology) or anti-eIF4G (1:100) antibody (Bethyl Labs) and gently shaken overnight at $4^{\circ} \mathrm{C}$. Supernatant/ antibody $(50 \mu \mathrm{l} / 100 \mu \mathrm{l})$ were added to a slurry of IgG bound to agarose beads (Pierce) and incubated with rocking at $25^{\circ} \mathrm{C}$ for $2 \mathrm{~h}$. Immunoprecipitates (IPs) were washed three times in lysis buffer plus CHAPS and once in wash buffer (in mM: 50 HEPES, pH 7.5, $40 \mathrm{NaCl}$, and 2 EDTA). An equal volume of SDS-PAGE buffer was added to the washed IP beads, and the resulting mixture was loaded directly on SDS-PAGE gels. Efficiency of the IP was determined by examining the abundance of the immunoprecipitated protein in the supernatant and wash fractions obtained from the procedure.

Western blot analysis. In brief, hippocampi or cortices were rapidly dissected, and transverse slices of dorsal hippocampus $(800 \mu \mathrm{m})$ were cut with a Mcllwain tissue chopper or Leica VT1200 vibratome and placed in ice-cold saline supplemented with a $1 \%$ cocktail of protease and phosphatase inhibitors (Sigma). Tissues were homogenized in lysis buffer containing the following (in mM): 5 HEPES, $1 \mathrm{MgCl}_{2}, 2$ EGTA, 1 DTT, and 300 sucrose, supplemented with the same protease/phosphatase inhibitor cocktail. Protein concentration was measured by means of the BCA assay (Pierce). Aliquots of protein $(30-40 \mu \mathrm{g})$ were subjected to SDSPAGE $(4-12 \%)$, transferred to a nitrocellulose membrane, and processed for incubation with primary antibodies, followed by secondary antibodies. Membranes were washed and reacted with enhanced chemiluminescence reagent (GE Healthcare). Band density values were normalized to $\beta$-actin or $\alpha$-tubulin. Mean band densities for samples from experimental animals were normalized to the corresponding samples from sham animals.

Antibodies. The following antibodies were used in this study: (1) two anti-phospho-Akt (Ser473 and Thr308) polyclonal antibodies (1:1000; Cell Signaling Technology), (2) an anti-Akt polyclonal antibody (1:1000; Cell Signaling Technology), (3) an anti-phospho-mTOR (Ser2481) polyclonal antibody (1:1000; Cell Signaling Technology), (4) an anti-mTOR rabbit monoclonal antibody (1:1000; Cell Signaling Technology), (5) an anti-phospho-S6 kinase (Thr389) mouse monoclonal antibody (1:1000; Cell Signaling Technology), (6) an anti-S6 kinase polyclonal antibody (1:1000; Cell Signaling Technology), (7i) an anti-4E-BP1 (1:1000; Cell Signaling Technology) polyclonal antibody, and (8) an anti- $\beta$-actin mouse monoclonal antibody (1:10,000; Sigma). Secondary antibodies were goat anti-rabbit IgG (1:4000; Vector Laboratories), except for phospho-S6 kinase and $\beta$-actin, in which case horse anti-mouse IgG was used (1:5000; Vector Laboratories).

Electrophysiology. Transverse hippocampal slices $(400 \mu \mathrm{m})$ were prepared from age-matched mice (4 weeks of age) using conventional techniques. Slices were maintained at $30^{\circ} \mathrm{C}$ in an interface chamber perfused with oxygenated ACSF containing the following (in $\mathrm{mM}$ ): $125 \mathrm{NaCl}, 2.5$ $\mathrm{KCl}, 125 \mathrm{NaH}_{2} \mathrm{PO}_{4}, 25 \mathrm{NaHCO}_{3}, 25 \mathrm{D}$-glucose, $2 \mathrm{CaCl}_{2}$, and $1 \mathrm{MgCl}_{2}(2$ $\mathrm{ml} / \mathrm{min}$ ). Extracellular field EPSPs (fEPSPs) were evoked by stimulation of Schaffer collateral pathway afferents and were measured by recording in the stratum radiatum of area CA1. Stable baseline synaptic transmission was established for $20-30 \mathrm{~min}$ with a stimulus intensity of $40-50 \%$ of the maximum fEPSP before LTD. LTD was induced by bath application of DHPG (100 $\mu \mathrm{M}, 5 \mathrm{~min})$. Incubation with rapamycin (20 nM) was for $40 \mathrm{~min}$ before application of DHPG. Data were collected and presented as the average slope of the baseline fEPSP recorded for $20 \mathrm{~min}$ before DHPG application. Individual traces were collected every $30 \mathrm{~s}$ for a total of 55 min after DHPG application and normalized to baseline fEPSP. Statistical analysis of electrophysiology data was performed by a one-way ANOVA and post hoc tests with significance assessed as $p<0.05$. 
mTOR activity assay. Area CA1 of the hippocampus was isolated from whole hippocampi dissected in ice-cold mTOR activity buffer. Extracted tissues were homogenized in assay buffer and prepared according to the K-LISA mTOR Activity kit (EMDCalbiochem). mTOR was purified from $200 \mu \mathrm{g}$ of starting material by immunoprecipitation using an mTOR antibody, 1:25 dilution, at $4^{\circ} \mathrm{C}$ overnight (Cell Signaling Technology). Immunoprecipitates were isolated by means of Protein-G Plus beads $(75 \mu \mathrm{l} / 150 \mu \mathrm{l}$ immunoprecipitate; Pierce) and rotation at $4^{\circ} \mathrm{C}$ for $3 \mathrm{~h}$. Purified mTOR was used for the activity assay according to the instructions of the manufacturer. mTOR activity was determined by ELISA, substrate absorbance was measured at $450 \mathrm{~nm}$, and reference wavelengths were measured at $540 / 595 \mathrm{~nm}$ by means of a Synergy 2 Multi-detection microplate reader (BioTek Instruments).

\section{Results}

mTOR signaling is important for capdependent translation (Klann and Dever, 2004) and essential for the expression of mGluR-LTD at Schaffer collateral to CA1 synapses (Hou and Klann, 2004). We first examined the abundance and phosphorylation of mTOR at Ser2448, a biochemical indicator of mTOR activation (Hay and Sonenberg, 2004), in the forebrain of Fmr1 KO mice. Phosphorylation of mTOR at Ser2448 was elevated in whole-cell lysates (increase to $53 \pm 18.9 \%$ of WT; $n=22$ WT; $n=18 \mathrm{KO} ; p<0.01$ ) (Fig. $1 A$ ) and isolated postsynaptic densities (supplemental Fig. S1, available at www.jneurosci.org as supplemental material) of the hippocampus of Fmr1 mutant mice at a young age (4-6 weeks old) and in whole-cell lysates of the hippocampus of Fmr1 mutant mice at an older age (6-8 months old) (increase to $138 \pm 47.7 \%$ of WT; $n=5 \mathrm{WT}$ and $\mathrm{KO} ; p<0.05$ ) (Fig. $1 B$ ) relative to that of age-matched WT littermates. Total mTOR abundance did not differ significantly in Fmr1 KO versus WT mice at either age examined (Fig. $1 A, B$ ) (supplemental Fig. S1, available at www. jneurosci.org as supplemental material). Similar results were observed in hippocampal lysates of C57BL/6 Fmr1 KO mice and WT littermates (supplemental Fig. S2, available at www.jneurosci.org as supplemental material). In contrast, in cortex, neither p-mTOR nor total mTOR differed in Fmr1 KO versus WT mice (Fig. 1C). Thus, mTOR phosphorylation is enhanced, consistent with the concept that mTOR signaling is overactivated, in the hippocampus (but not the cortex) of Fmr1 KO mice.

Because mTOR protein abundance and Ser2448 phosphorylation status do not necessarily predict mTOR function, we used four independent experimental approaches to examine mTOR $0.01 ;{ }^{* * *} p<0.001$.
A

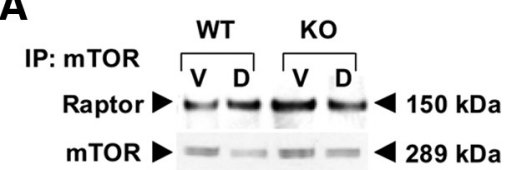

Input
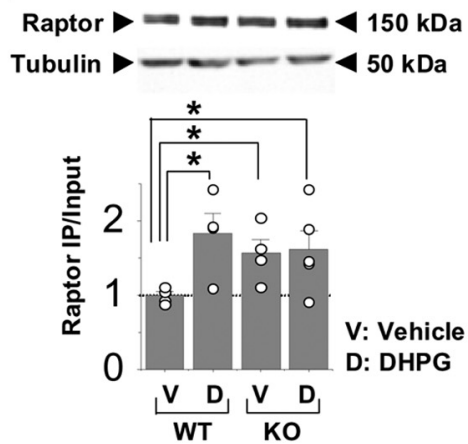

D
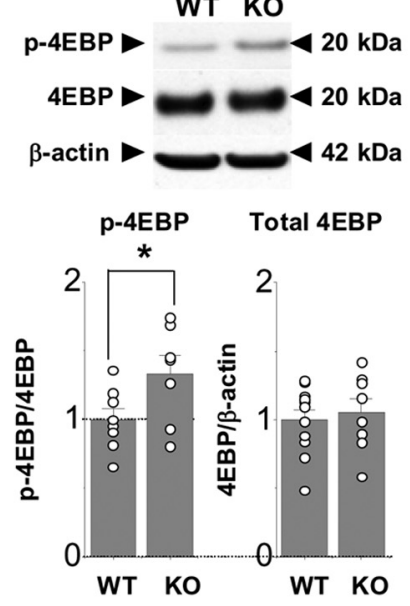

B

C

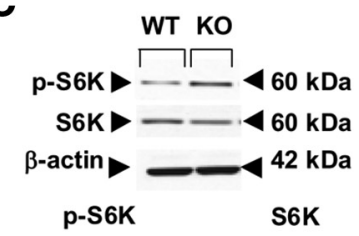

E

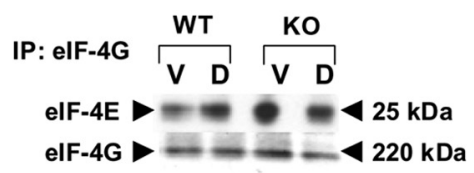

Input
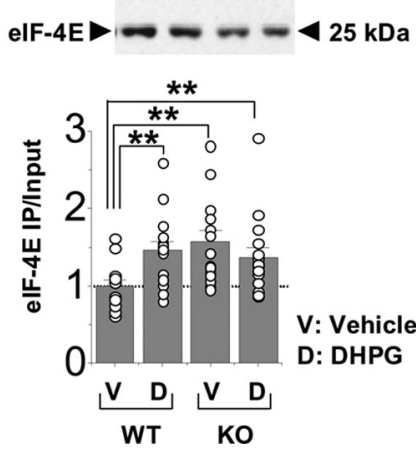

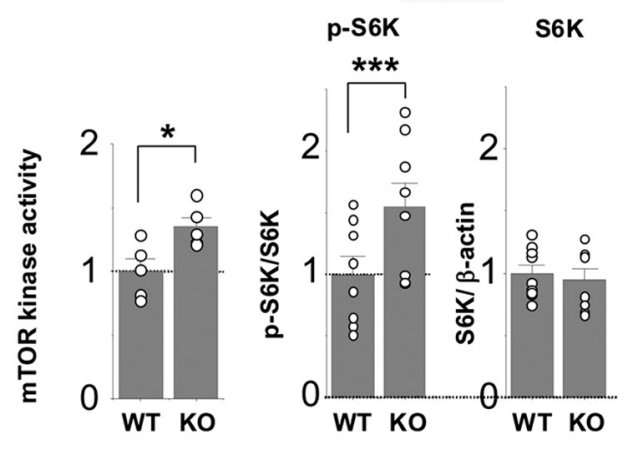

Figure 2. mTOR functional activity is enhanced in young fragile X mice. $A$, Association of mTOR with raptor is enhanced and DHPG insensitive in hippocampal slices from Fmr1 KO mice. Representative Western blots (top) and summary data (bottom) for immunoprecipitation with an antibody to mTOR and immunoblotting with an antibody to raptor in lysates prepared from hippocampal slices of Fmr $1 \mathrm{KO}$ mice and WT littermates treated with either DHPG (100 $\mu \mathrm{M}, 10 \mathrm{~min})$ or vehicle. $\boldsymbol{B}$, mTOR kinase activity is elevated in hippocampal lysates of Fmr1 KO mice (KO, increase to $154 \pm 6.9 \%$ of WT; $n=8$ per genotype; $p<0.05$ ). mTOR activity was assayed using a purified S6K substrate to determine abundance of p-Thr389-S6K relative to that of total S6K. C, Phosphorylation of S6K at Thr389 is enhanced in the hippocampus of Fmr $1 \mathrm{KO}$ animals (KO, increase to $132 \pm 5.6 \%$ of WT; $n=$ $7 ; p<0.05$ ). Representative Western blots (top) and summary data (bottom) showing relative abundance of $p$-Thr389-S6 kinase and total S6K in whole-cell hippocampal lysates from Fmr $1 \mathrm{KO}$ mice and WT littermates. Westerns were probed with antibodies to p-Thr389-S6K and total S6K. D, Phosphorylation of translational initiation inhibitor 4E-BP at Thr37/46 is enhanced in the hippocampus of Fmr1 KO mice (KO, increase to $133 \pm 0.08 \%$ of WT; $n=8 ; p<0.05$ ). Representative Western blots (top) and summary data (bottom) showing relative abundance of p-Thr37/46-4E-BP1 (left) and total 4E-BP (right) in hippocampal lysates from Fmr1 KO mice and WT littermates. Western blots were probed with antibodies to $\mathrm{p}$-Thr37/46-4E-BP1 and total 4E-BP. $\boldsymbol{E}$, Formation of the translation initiation complex is enhanced and DHPG insensitive in Fmr $1 \mathrm{KO}$ mice. Representative Western blots (top) and summary data (bottom) for coimmunoprecipitation of elF4G with elF4E in lysates prepared from hippocampal slices of Fmr1 KO mice and WT littermates treated as in $\boldsymbol{A}$. Western blots were probed with antibodies to elF4G and elF4E. Association of elF4E with elF4G is enhanced in Fmr $1 \mathrm{KO}$ mice under basal conditions and is insensitive to stimulation by DHPG. ${ }^{*} p<0.05$; ${ }^{* *} p<$

kinase activity in Fmr1 KO mice. First, we examined the association of raptor with mTOR under basal and group I mGluRstimulated conditions, a functional readout of mTOR activity required for translation initiation (Kim and Sabatini, 2004). Raptor is a critical component of mTOR complex 1 (mTORC1) and serves as a scaffold to spatially position substrates in close proximity to mTOR (Hara et al., 2002; Kim et al., 2002; Nojima et al., 2003). Association of raptor with mTOR promotes mTOR- 
A

WT

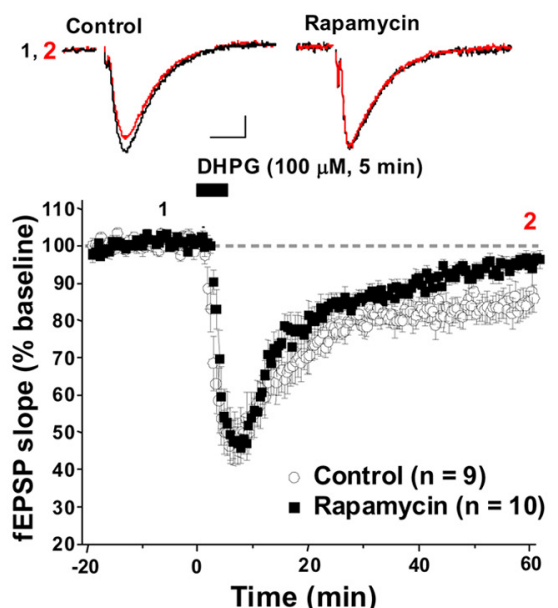

B

\section{Fmr1 KO}
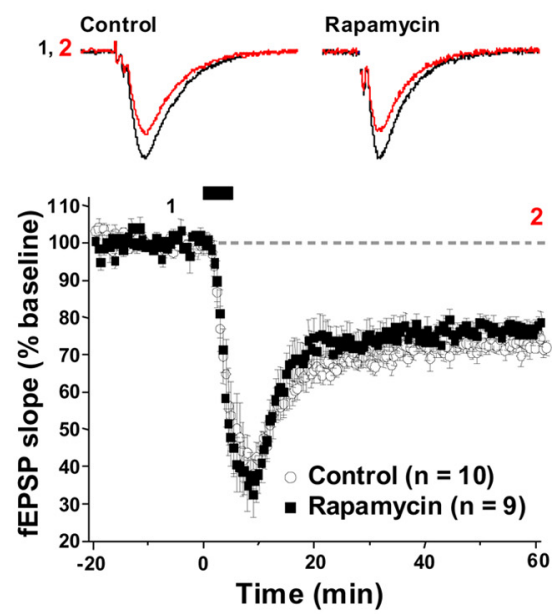

Fmr1 KO

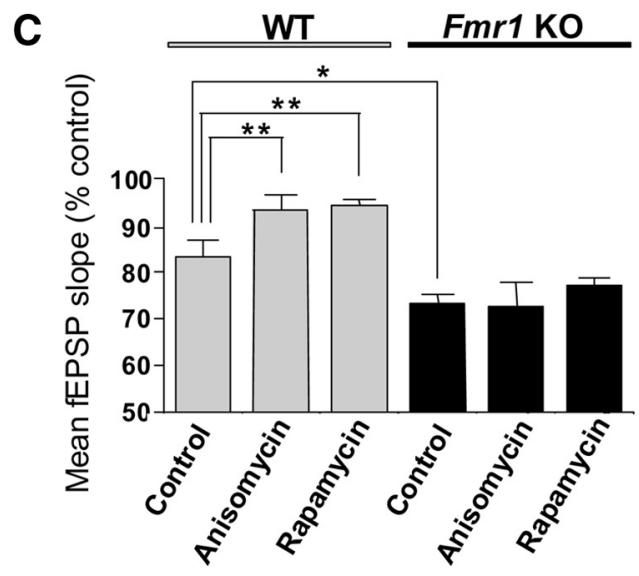

Figure 3. Rapamycin does not block exaggerated mGluR-LTD in Fmr1 K0 mice. After 20 min stable baseline recording, mGluRLTD was elicited by bath application of DHPG (100 $\mu \mathrm{m}, 5 \mathrm{~min})$ in the absence or presence of the protein synthesis inhibitor anisomycin $(20 \mu \mathrm{M})$ or the selective mTOR inhibitor rapamycin (20 nM) to acute hippocampal slices from WT $(\boldsymbol{A})$ and $F m r 1 \mathrm{KO}(\boldsymbol{B})$ mice at 4 weeks of age. mGluR-LTD was exaggerated in acute hippocampal slices from Fmr 1 KO versus WT mice. In WT slices, mGluR-LTD was blocked by anisomycin and rapamycin; in KO slices, anisomycin and rapamycin had little or no effect on mGluR-LTD (Fmr 1 KO plus rapamycin, fEPSP slope of $77 \pm 2 \%$ of baseline, $n=9$; WT plus rapamycin, fEPSP slope of $94 \pm 1 \%$ of baseline, $n=$ $10 ; p<0.001)$. Drugs were present in the perfusion solution from $20 \mathrm{~min}$ before and during treatment with DHPG as indicated by the bars. Summary data are shown in $C$. ${ }^{*} p<0.05 ;{ }^{* *} p<0.01$.

dependent phosphorylation of S6K in vitro (Hara et al., 2002; Kim et al., 2002; Nojima et al., 2003). Toward this end, we incubated acute hippocampal slices from young (4-6 weeks old) Fmr1 KO mice and WT littermate controls with the group I mGluR agonist DHPG (100 $\mu \mathrm{m}$ for $10 \mathrm{~min}$ ) and processed slices for Western blot analysis and immunoprecipitated mTOR, followed by immunoblotting with an antibody against raptor (Fig. $2 A)$. Under basal conditions, association of mTOR with raptor (expressed as the ratio of raptor in the IP to raptor in the input) was greater in lysates from Fmrl KO versus WT mice, indicative of enhanced basal mTORC1 activity (Fig. $2 A$ ). In acute hippocampal slices from WT mice, DHPG enhanced mTOR/raptor association (expressed as the ratio of raptor in the IP to raptor in the input). In contrast, DHPG did not detectably alter mTOR/ raptor association in slices from Fmrl KO mice (Fig. 2A). Similar results were obtained when association of $\mathrm{mTOR}$ with raptor was expressed as the ratio of raptor in the IP to mTOR in the input (data not illustrated). These findings indicate that mTOR signaling is upregulated under basal conditions in the hippocampus of the Fmr1 KO mouse and are consistent with a model whereby the mTORC1 complex (and mTOR activity) is at or near saturating levels under basal conditions and thus cannot be further enhanced by mGluR stimulation.

To more directly address mTOR functional activity, we used an in vitro assay to measure mTOR kinase activity. Toward this end, we prepared lysates from hippocampal area CA1 of Fmrl $\mathrm{KO}$ and WT mice, isolated mTOR by immunoprecipitation, and examined mTOR kinase activity using purified recombinant $\mathrm{S} 6 \mathrm{~K}$ as a substrate. $\mathrm{S} 6 \mathrm{~K}$ is a protein kinase critical to initiation of TOP-dependent translation and is a downstream target of mTOR. Hippocampal lysates from Fmr1 KO mice exhibited increased mTOR kinase activity (increase to $32 \pm 5.6 \%$ of WT; $n=7 ; p=$ 0.027 ) (Fig. $2 B$ ). To assess whether the observed increase in mTOR activity in the hippocampus could also be observed in vivo, we measured the phosphorylation status of S6K (Hay and Sonenberg, 2004). Phosphorylation of S6K at Thr389 was significantly higher in hippocampal lysates of young Fmr1 mutant mice compared with WT littermates (increase to $54 \pm 6.9 \%$ of WT; $n=8 ; p<0.05$ ) (Fig. $2 C)$. The increase in steady-state phosphorylation of S6K was very similar to that observed for the magnitude of mGluR-LTD in acute hippocampal slices of KO versus WT mice, consistent with the notion that basal hippocampal mTOR activity is at or near maximal levels in the hippocampus of Fmr1 KO mice.

We next measured formation of the eIF4F initiation complex, a critical first step in cap-dependent translation. Under basal conditions, 4E-BP binds eIF4E and inhibits its association with eIF4G (Klann and Dever, 2004). During activation, mTOR phosphorylates $4 \mathrm{E}-\mathrm{BP}$, promoting its release from eIF4E, enabling eIF4E to associate with eIF4G. The eIF4G/eIF4E complex associates with eIF4A to form the initiation complex eIF4F, a critical step in cap-dependent translation (Klann and Dever, 2004). We first examined phosphorylation status of 4E-BP, which should increase during mTOR activation. As expected, phosphorylation status of 4E-BP was elevated in hippocampus of Fmr 1 KO mice (increase to $33 \pm 0.08 \%$ of WT; $n=8 ; p<0.05$ vs WT) (Fig. 2D). To assay translation initiation complex formation, eIF4F levels, we incubated hippocampal slices in the absence or presence of DHPG $(100 \mu \mathrm{M})$, prepared lysates, immunoprecipitated with an antibody to eIF4G, and probed Western blots with an antibody to eIF4E. We found that association of eIF4G with eIF4E under basal conditions (expressed as the ratio of eIF4E in the IP to eIF4E in the input) was significantly higher in the hippocampus of Fmr1 KO mice relative to that of WT littermates (Fig. 2E). Moreover, in slices from Fmrl KO mice, formation of the initiation complex (expressed as the ratio of eIF4E in the IP to 
eIF4E in the input) was not detectably altered by DHPG stimulation. Similar results were obtained when association of eIF4G with eIF4E was expressed as the ratio of eIF4E in the IP to eIF4G in the input (data not illustrated). Thus, basal levels of eIF4F are elevated in Fmr1 KO mice, and this increase appears to occlude the DHPG-induced increase in formation of the eIF4F complex normally observed in WT mice (Banko et al., 2006).

The results so far demonstrate that mTOR phosphorylation and activity are enhanced in the fragile $\mathrm{X}$ mouse but do not address the impact of enhanced mTOR signaling on synaptic function. To address this issue, we examined a possible requirement for $\mathrm{mTOR}$ signaling in mGluR-dependent synaptic plasticity at CA1 synapses in acute hippocampal slices from the fragile X mouse. Fmr1 KO mice exhibited exaggerated mGluR-LTD relative to that of WT mice (Fig. 3A,B) (Fmr1 KO mice, fEPSP slope of $73 \pm 2 \%$ of baseline, $n=10$; WT, fEPSP slope of $83 \pm 3 \%$ of baseline, $n=8 ; p=0.01574$ ) corroborating previous results (Huber et al., 2002; Hou and Klann, 2004). Moreover, in the KO mouse, mGluR-LTD was insensitive to the protein synthesis inhibitor anisomysin (Fig. 3A,B) (Fmr1 KO mice, fEPSP slope of $73 \pm 5 \%$ of baseline, $n=7$; WT anisomysin, fEPSP slope of $93 \pm 3 \%$ of baseline, $n=7 ; p=0.0058$ ) corroborating previous results (Hou et al., 2006; Nosyreva and Huber, 2006). These findings are consistent with the notion that mGluR signaling is overactivated and that mGluR-LTD is protein synthesis independent at CA1 synapses of the $\mathrm{KO}$ mouse. The findings are also consistent with observations that activation of group I mGluRs promotes local protein synthesis of synaptic proteins (Weiler and Greenough, 1993; Angenstein et al., 1998; Banko et al., 2006).

In WT mice, mGluR-LTD requires mTOR signaling (Hou and Klann, 2004). To examine a possible role for $\mathrm{mTOR}$ in the exaggerated mGluR-LTD observed at CA1 synapses of Fmr1 KO mice, we next treated acute hippocampal slices with DHPG or vehicle in the absence or presence of the specific mTOR inhibitor rapamycin. Treatment of hippocampal slices with rapamycin (20 nM) abolished DHPG-elicited mGluR-LTD in WT mice, consistent with previous reports (Hou and Klann, 2004). In contrast, rapamycin did not alter mGluR-LTD in the Fmr1 KO mice (Fmr1 KO plus rapamycin, fEPSP slope of $77 \pm$ $2 \%$ of baseline, $n=9$; WT plus rapamycin, fEPSP slope of $94 \pm$ $1 \%$ of baseline, $n=10 ; p<0.0001$ ) (Fig. $3 A, B$ ). These findings indicate that DHPG-induced mGluR-LTD is exaggerated and both protein synthesis and mTOR-independent in Fmrl KO mice.

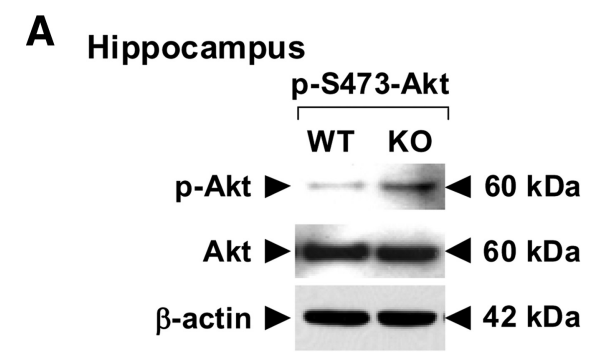

B
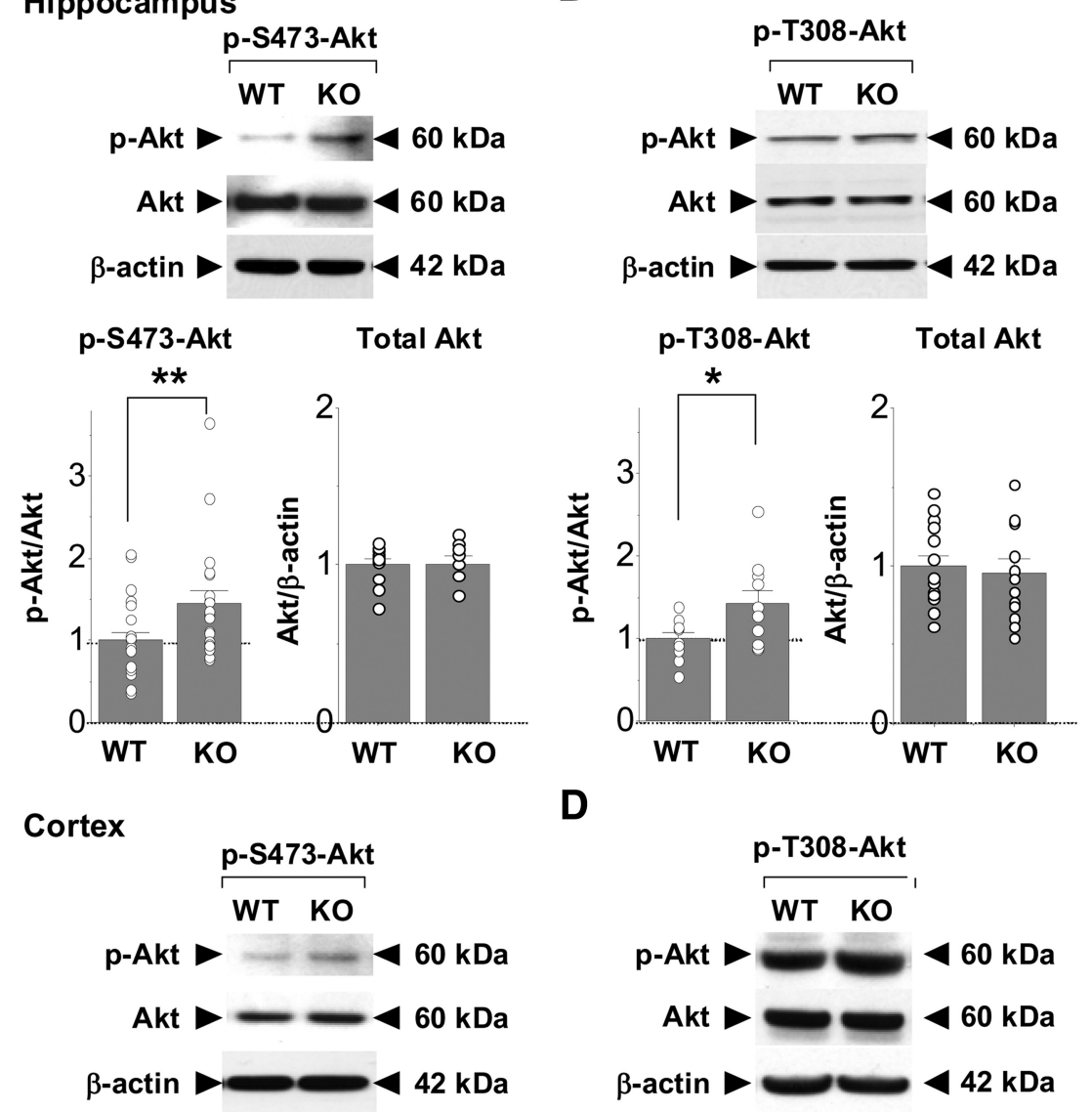

D
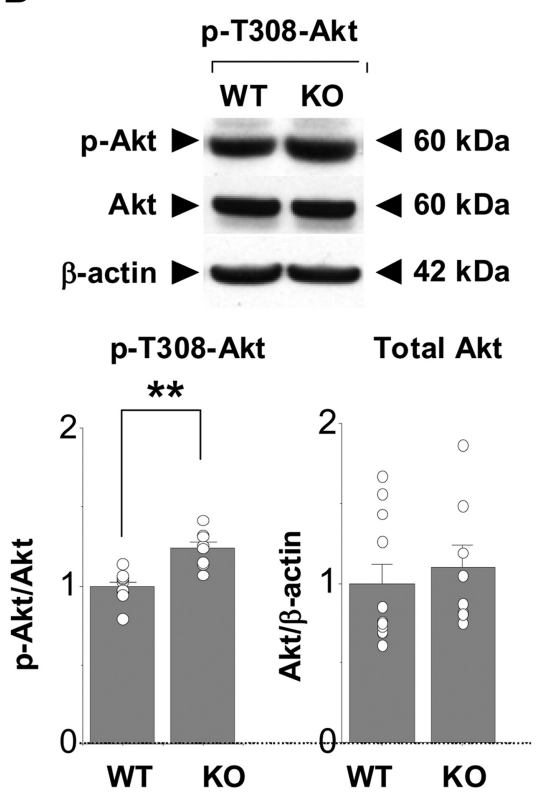

Figure 4. Akt phosphorylation is enhanced in the hippocampus and cortex of young fragile $X$ mice. Representative Western blots (top) and summary data (bottom) showing p-Akt and total Akt in whole-cell lysates from the hippocampus $(\boldsymbol{A}, \boldsymbol{B})$ and cortex $(\boldsymbol{C}, \boldsymbol{D})$ from Fmr1 K0 mice and WT littermates. Western blots were probed with antibodies against p-Ser473 $(\boldsymbol{A}, \boldsymbol{C})$ and p-Thr308 $(\boldsymbol{B}, \boldsymbol{D})$ Akt, stripped, and reprobed with an antibody against Akt to determine total Akt levels. Phosphorylation of Akt at Ser473 (hippocampus: increase to $28 \pm 8 \%$ of WT, $n=20 \mathrm{WT}, n=18 \mathrm{KO},{ }^{*} p<0.05$; cortex: increase to $96 \pm 33 \%$ of WT, $n=9$ WT, $n=7 \mathrm{KO},{ }^{*} p<0.05$ ) and Thr308 (hippocampus: increase to $28 \pm 8 \%$ of WT, $n=20 \mathrm{WT}, n=18 \mathrm{KO},{ }^{*} p<0.05$; cortex: increase to $24 \pm 3 \%$ of WT, $n=7,{ }^{*} p<0.05$ ) are enhanced in hippocampus and cortex of young Fmr 1 K0 animals. ${ }^{*} p<0.05 ;{ }^{* *} p<0.01$.

The findings reported thus far show that mTOR signaling is enhanced in the hippocampus of Fmr1 KO mice but do not address the mechanism by which mTOR activity is increased. The PI3K/Akt signaling pathway is a well established kinase system upstream of mTOR (Sarbassov et al., 2005b). Therefore, we examined phosphorylation of Akt at two sites, Ser473 and Thr308, both of which are indicators of Akt kinase activation. First, we examined phosphorylation of Akt at Ser473 and found that it was enhanced in hippocampal and cortical tissues from young (4-6 weeks old) Fmr1 KO versus WT mice (hippocampus: increase to $28 \pm 8 \%$ of WT, $n=20 \mathrm{WT}, n=18 \mathrm{KO}, p=0.003$; cortex: 
A

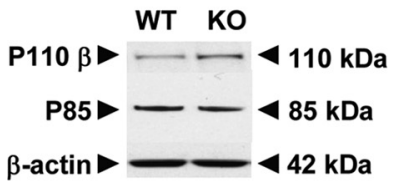

$\mathrm{PI3K}, \mathrm{P} 110 \beta$

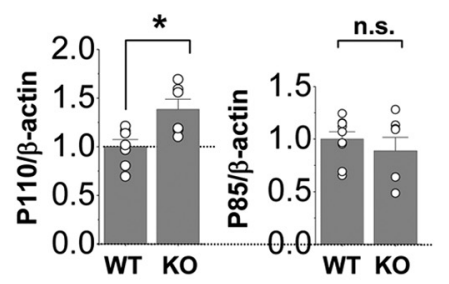

C

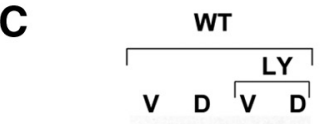

p-mTOR - - $-4289 \mathrm{kDa}$
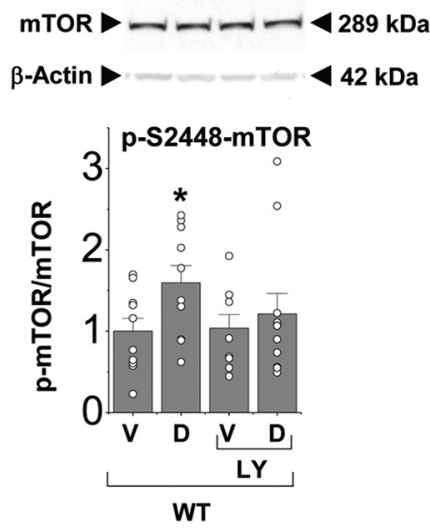

Total mTOR

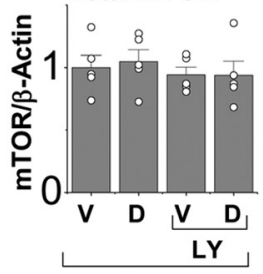

WT
B

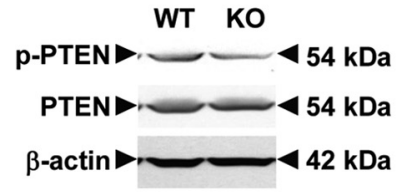

p-S380/T382/T383-PTEN Total PTEN

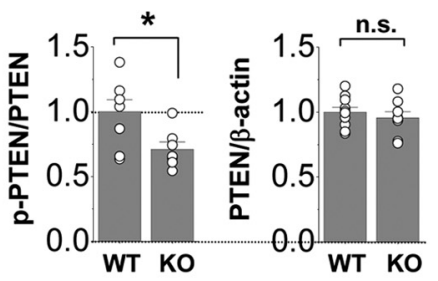

KO
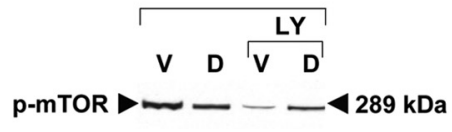

mTOR - - - $-4289 \mathrm{kDa}$

$\beta$-Actin $\longrightarrow-\longrightarrow-42 \mathrm{kDa}$

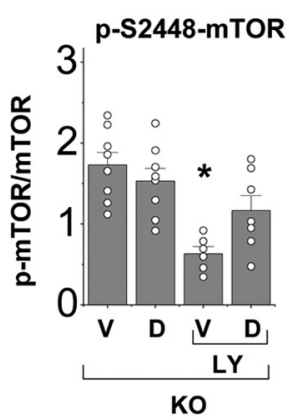

V: Vehicle D: DHPG LY: LY 294002

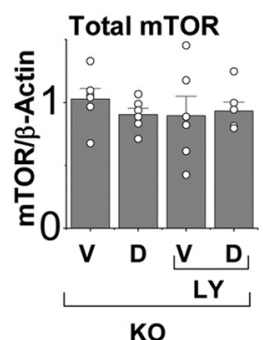

KO

Figure 5. PI3K p110 $\beta$ catalytic subunit abundance is increased and PTEN phosphorylation is decreased in Fmr1 K0 mice. $A$, Representative Western blots and summary bar graphs of PI3K, p110 $\beta$, and p85 subunits in lysates from the hippocampus of Fmr $1 \mathrm{KO}$ mice and WT littermates. Western blots indicate that, whereas $p 110 \beta$ subunit expression is increased (increase to $38 \pm$ $3 \%$ of WT; $n=7 \mathrm{WT} ; n=6 \mathrm{KO} ; p=0.02$ ) in Fmr1 K0 mice, there is little or no change in PI3K p85 subunit. $\boldsymbol{B}$, Representative Western blots and summary bar graphs of p-PTEN and total PTEN in hippocampal lysates from young Fmr1 KO mice and WT littermates. Western blots were probed with antibodies against p-Ser380/Thr382/383-PTEN, stripped, and reprobed with an antibody against PTEN to determine total PTEN levels (decrease to $28.9 \pm 5.5 \%$ of WT; WT, $n=8 ; \mathrm{KO}, n=7 ; p<0.05$ vs WT). C, The PI3K inhibitor LY294002 reduces mTOR phosphorylation and restores DHPG sensitivity in KO mice. Representative Western blots (top) and summary data (bottom) showing p-Ser2448 -mTOR and total mTOR in hippocampal slices incubated in LY294002 ( $50 \mu \mathrm{m}, 40 \mathrm{~min}$ ) or vehicle, followed by DHPG (100 $\mu \mathrm{m}, 10 \mathrm{~min}$ ) or vehicle. These findings indicate a causal relationship between elevated PI3K/Akt signaling and elevated mTOR activity in Fmr 1 hippocampus. ${ }^{*} p<0.05$.

increase to $96 \pm 33 \%$ of WT, $n=9 \mathrm{WT}, n=7 \mathrm{KO}, p<0.05$ ) (Fig. $4 A, C)$. We next examined phosphorylation of Akt at Thr308 (p-Thr308), a second site implicated in Akt kinase activity. Western blot analysis revealed that phosphorylation of Akt was enhanced at Thr308 in hippocampal and cortical tissues from fragile X mice versus WT (Fig. $4 B, D$ ). The differences in phospho-Akt appear to be attributable to alterations in basal ac- tivation states, because total Akt abundance did not differ significantly in mutant mice relative to WT littermates (Fig. 4).

Increased Akt phosphorylation could be achieved by activation of PI3K, which is an important kinase upstream of Akt and downstream of mGluRs (Endersby and Baker, 2008). Moreover, the mRNAs encoding the PI3K subunits p85 and p110 are thought to be direct targets of FMRP (Brown et al., 2001). PTEN (phosphatase and tensin homolog deleted on chromosome ten) is an upstream suppressor of mTOR signaling and an important negative regulator of PI3K signaling (Endersby and Baker, 2008). To test these possibilities, we examined PI3K protein abundance in lysates isolated from the hippocampus of young Fmr1 KO mice and their WT littermates. Western blot analysis revealed that levels of the p110 $\beta$ catalytic subunit of PI3K were elevated in Fmr1 KO mice (increase to $38 \pm 3 \%$ of WT; $n=7 \mathrm{WT}$; $n=$ $6 \mathrm{KO} ; p=0.02)$ and that there was little or no change in p85 subunit abundance compared with their WT littermates (Fig. $5 A)$. In contrast, phosphorylation of PTEN at Ser380/Thr382/383 was decreased in Fmr1 KO versus WT mice (decrease to $28.9 \pm 5.5 \%$ of WT; WT, $n=8$; $\mathrm{KO}, n=7 ; p<0.05$ versus WT) (Fig. $5 B$ ). Whereas enhanced abundance of the PI3K p $110 \beta$ catalytic subunit is indicative of enhanced PI3K activity, dephosphorylation of PTEN (an upstream suppressor of PI3K) is indicative of enhanced activity, stabilization, and localization of PTEN to the inner face of the plasma membrane in Fmr1-deficient mice (Leslie et al., 2008). Thus, elevated Akt phosphorylation in the Fmr1 KO mice is likely attributable to increased levels of the p110 $\beta$ subunit of PI3K, which cannot be overcome by enhanced PTEN phosphatase activity.

The results thus far show that pAkt and mTOR signaling are elevated in the hippocampus of fragile $\mathrm{X}$ mice but do not address a possible causal relation between the two. To address this issue, we asked whether pretreatment of slices with the specific PI3K inhibitor LY294002 [2(4-morpholinyl)-8-phenyl-1(4H)-benzopyran-4-one] could correct aberrant mTOR phosphorylation. Preincubation with LY294002 (50 $\mu \mathrm{M}, 40 \mathrm{~min})$ caused a decrease in phospho-mTOR in the hippocampus of wild-type mice to wild-type levels and restored sensitivity of mTOR to DHPG stimulation in KO neurons (Fig. 5D).

The findings thus far document enhanced mTOR signaling pathway in KO mice but do not establish a possible link between loss of FMRP and overactivated mTOR signaling. PIKE is a small (753 aa) nuclear GTPase and upstream activator of nuclear PI3K (Ye et al., 2000; Rong et al., 2003). Moreover, PIKE is an identified 
target of FMRP (J. Darnell, personal communication). We next examined PIKE abundance in the hippocampus of fragile X mice. PIKE exists as two brain-specific isoforms, the short splice variant PIKE-S, which is present in the nucleus and is known to activate PI3K, and the long splice form PIKE-L, which localizes to the nucleus and cytoplasm, where it binds to the adaptor protein and mGluR1/5 binding partner Homer (Rong et al., 2003). PIKE-S abundance was enhanced in whole-cell hippocampal lysates (increase to $35 \pm 2.6 \%$ of WT; $n=9 ; p<0.01$ ) (Fig. 6 , top) and postsynaptic densities (supplemental Fig. S1, available at www. jneurosci.org as supplemental material) from Fmr1 KO mice. In contrast, PIKE-L expression did not differ significantly from that of wild type (Fig. 6, bottom) (supplemental Fig. S1, available at www.jneurosci.org as supplemental material). These findings are consistent with a model whereby, in wild-type mice, FMRP represses translation of PIKE-S; in KO hippocampal neurons, elevated PIKE-S promotes enhanced activity of nuclear PI3K, which in turn promotes elevated mTOR signaling.

\section{Discussion}

Fragile X syndrome is the most common heritable form of mental retardation and a leading genetic cause of autism (Hagerman and Hagerman, 2002; Jacquemont et al., 2007; Loesch et al., 2007). A hallmark feature of the Fmr1 knock-out mouse is overactivation of group I mGluR signaling and exaggerated mGluR-LTD. Activation of group I mGluRs promotes mTOR signaling (Hou and Klann, 2004; Banko et al., 2006) and drives mTORdependent protein synthesis in dendrites (Weiler et al., 1997). Components of the mTOR signaling cascade are present at synapses and mediate synaptic plasticity via regulation of local protein synthesis (Tang et al., 2002). The present study shows that mTOR signaling is overactivated in the hippocampus of the fragile $\mathrm{X}$ mouse as assessed by four functional readouts: (1) association of raptor with mTOR, (2) kinase activity, (3) phosphorylation of the mTOR downstream targets S6K and 4E-BP, and (4) formation of the initiation complex $4 \mathrm{~F}$ (eIF4F), a critical first step in initiation of cap-dependent translation in dendrites (Klann and Dever, 2004). Consistent with these observations, mGluR-LTD at Schaffer collateral to CA1 pyramidal cell synapses of the Fmrl knockout mouse is exaggerated and rapamycin insensitive. We further show that abundance of the p $110 \beta$ (but not p85) subunit of PI3K, an upstream regulator of $\mathrm{mTOR}$, is elevated in the hippocampus of the Fmrl KO mouse. The RNA encoding the $110 \beta$ subunit contains several potential consensus G-quartet sequences in the coding and 3' untranslated region, providing a potential link between FMRP function and $\mathrm{PI} 3 \mathrm{~K}$ protein expression. Interestingly, both the mRNA encoding the 110 subunit (Miyashiro et al., 2003) and the mRNA encoding the p85 subunit (Brown et al., 2001) are putative targets of FMRP, yet p85 expression is unchanged in the Fmrl KO mouse. We further show that the PI3K inhibitor LY294002 re-

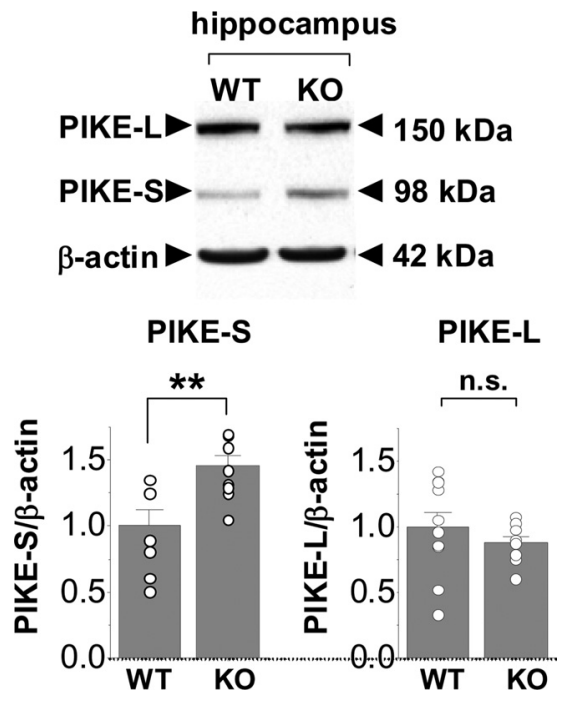

Figure 6. PIKE-S, but not PIKE-L, abundance is increased in Fmr1 KO mice. Expression of PIKE-S, a known target of FMRP (J. Darnell, personal communication) and upstream regulator of PI3K (Ye et al., 2000), is enhanced in hippocampal lysates from Fmr $1 \mathrm{KO}$ mice. Representative Western blots (top) and summary data (bottom) showing PIKE-S and PIKE-L in lysates from the hippocampus of Fmr1 KO mice and WT littermates. Whereas PIKE-S expression is increased (increase to $35 \pm 2.6 \%$ of WT; $n=9 \mathrm{WT} ; n=9 \mathrm{~K} 0 ; p=0.027$ ), there is little or no change in PIKE-I (NS) in the hippocampus of Fmr1 K0 mice. ${ }^{* *} p<0.01$.

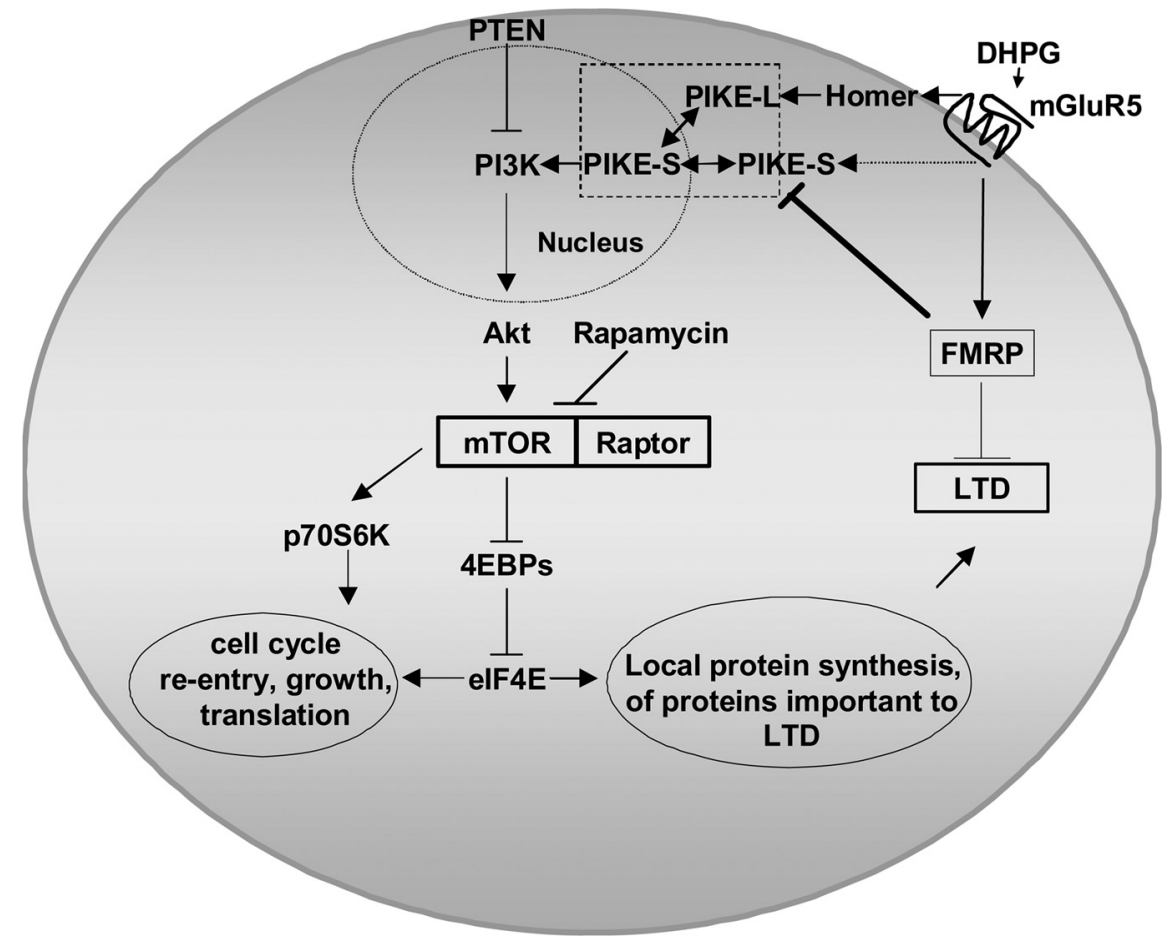

Figure 7. Model showing possible interaction of FMRP with the mTORC1 complex. In wild-type mice, FMRP represses PIKE or other endogenous activator of PI3K/Akt signaling and thereby exerts a negative regulatory effect on mTORsignaling. Activation of group ImGluRs by the agonist DHPG promotes formation of an mGluR-Homer-PIKE complex, which engages PI3K/Akt signaling (Rong et al., 2003). PI3K/Akt in turn stimulates mTOR signaling, initiation of translation of synaptic proteins in dendrites, and mGluR-LTD. In FMRP-deficient mice, the positive effector (PIKE) is upregulated and mTOR signaling is overactivated and DHPG insensitive, leading to aberrant synthesis of synaptic proteins and exaggerated protein synthesis-independent mGluR-LTD. The PI3K inhibitor LY294002 reduces p-mTOR to wild-type levels and restores DHPG sensitivity.

duces p-mTOR to wild-type levels and restores DHPG sensitivity, consistent with a causal relationship between elevated PI3K/Akt signaling and elevated mTOR. Moreover, PIKE, an upstream regulator of PI3K and identified target of FMRP (J. Darnell, 
personal communication) is also elevated. Collectively, these findings suggest that exaggerated mTOR signaling may serve as a functional link between overactivation of group I mGluRs and aberrant synaptic plasticity at CA1 synapses of the fragile $\mathrm{X}$ mouse.

Our observation that mGluR-LTD at CA1 synapses of WT mice is rapamycin sensitive is consistent with findings of others (Hou and Klann, 2004) and extend those findings by showing for the first time that exaggerated mGluR-LTD in Fmr1 KO mice is rapamycin insensitive. Whereas our observation that mTOR and S6K phosphorylation are enhanced in Fmr1 KO mice under basal conditions differs from findings of Ronesi and Huber (2008) that p-mTOR and p-S6K are unaltered under basal conditions, our finding that mTOR phosphorylation is DHPG insensitive in Fmr1 KO mice is consistent with their findings. A possible explanation for the differences in the results in the two studies is the use of different strains of the Fmr1 KO mice (FVB in the current study vs C57BL/ 6 in the case of Ronesi and Huber). Differences in mTOR activity could contribute to the known differences in the behavioral phenotypes of these two strains (R. Paylor, personal communication). Our findings extend previous studies in that we examine functional readouts of mTOR activity in addition to phosphorylation status.

Our observations that exaggerated mGluR-LTD in Fmr1 KO mice is rapamycin and anisomycin insensitive are consistent with findings of others (Huber et al., 2002; Hou and Klann, 2004; Hou et al., 2006; Nosyreva and Huber, 2006; Zhang et al., 2009). As suggested by these investigators, because protein synthesis is overactivated in the hippocampus of $\mathrm{KO}$ mice, it is likely that protein(s) required for mGluR-LTD have already accumulated at synapses under basal conditions and before induction of mGluRLTD. Our observations that mTOR phosphorylation is DHPG insensitive and that mGluR-LTD is rapamycin insensitive are consistent with observations that sensitization to spinal nociception in response to formalin-induced pain is DHPG and rapamycin insensitive in Fmr1 KO mice (Price et al., 2007).

Our findings that PI3K and PTEN are aberrantly activated in Fmr1 KO mice are of interest given that dysregulation of these proteins are implicated in autism spectrum disorders. During activation, Akt phosphorylates its downstream target tuberin, the gene product of TSC2 (Luo et al., 2003). Individuals with loss-offunction mutations in TSC1 and TSC2 exhibit behavioral abnormalities, including autism (Wiznitzer, 2004). Akt hypofunction is associated with schizophrenia and increased susceptibility to Parkinson's disease (Emamian et al., 2004; Greggio and Singleton, 2007). A novel finding of the present study is that PTEN phosphorylation is reduced in the fragile $\mathrm{X}$ mouse (Fig. $5 B)$. Dephosphorylation of PTEN is associated with enhanced PTEN activation, stability, and translocation from the cytoplasm to signaling sites on the plasma membrane in which it is strategically positioned in close proximity to substrates (Leslie et al., 2008). During activation, PTEN dephosphorylates phosphatidylinositol-3,4,5-triphosphate, converting it to phosphatidylinositol4,5-biphosphate, which in turn reduces Akt phosphorylation and activation. A possible scenario is that inhibitory pathways acting upstream of mTOR signaling such as PTEN are engaged to compensate for overactivation of mTOR and the translational machinery at synapses. Our finding that PTEN phosphorylation is altered in the Fmr1 knock-out mouse is of interest in that individuals with germline PTEN mutations display mood disorders and mental retardation (Waite and Eng, 2002), and PTEN mutations have been reported in individuals with autism (Zori et al., 1998; Goffin et al., 2001; Butler et al., 2005).
Findings in the present study are consistent with a model whereby, in hippocampal neurons of wild-type mice, FMRP represses PIKE (or other endogenous activator of PI3K/Akt signaling) and thereby exerts a negative regulatory effect on mTOR signaling (Fig. 7). In KO mice, PIKE-S is derepressed and promotes enhanced activation of nuclear PI3K, which in turn promotes elevated mTOR signaling. PIKE is a predicted target of FMRP (J. Darnell, personal communication) and upstream regulator of PI3K (Ye et al., 2000). At least two brain-specific isoforms of PIKE exist: PIKE-S, which localizes to the nucleus and is known to activate PI3K via its GTPase activity, and PIKE-L, which is cytoplasmic and binds to the immediate early gene product, scaffolding protein, and group I mGluR binding partner Homer (Rong et al., 2003). Thus, FMRP acts upstream of mTOR signaling to blunt mTOR activity. We predict that in WT mice activation of group I mGluRs by the agonist DHPG stimulates mTOR signaling, initiation of translation of synaptic proteins in dendrites, and mGluR-LTD. In FMRP-deficient mice, PIKE is upregulated; mTOR signaling is overactivated and DHPG insensitive, leading to aberrant synthesis and accumulation of synaptic proteins and exaggerated protein synthesis-independent mGluR-LTD.

An important prediction of this model is that dysregulation of mTOR signaling and aberrant mTOR-dependent, capdependent protein translation contribute to the cognitive and social interaction deficits observed in humans with fragile X syndrome. Findings in our study implicate components of the mTOR signaling cascade as novel targets for therapeutic strategies for amelioration of plasticity and cognitive deficits in neurobehavioral disorders.

\section{References}

Angenstein F, Greenough WT, Weiler IJ (1998) Metabotropic glutamate receptor-initiated translocation of protein kinase p90rsk to polyribosomes: a possible factor regulating synaptic protein synthesis. Proc Natl Acad Sci U S A 95:15078-15083.

Bagni C, Greenough WT (2005) From mRNP trafficking to spine dysmorphogenesis: the roots of fragile X syndrome. Nat Rev Neurosci 6:376-387.

Banko JL, Hou L, Poulin F, Sonenberg N, Klann E (2006) Regulation of eukaryotic initiation factor $4 \mathrm{E}$ by converging signaling pathways during metabotropic glutamate receptor-dependent long-term depression. J Neurosci 26:2167-2173.

Brown V, Jin P, Ceman S, Darnell JC, O’Donnell WT, Tenenbaum SA, Jin X, Feng Y, Wilkinson KD, Keene JD, Darnell RB, Warren ST (2001) Microarray identification of FMRP-associated brain mRNAs and altered mRNA translational profiles in fragile X syndrome. Cell 107:477-487.

Butler MG, Dasouki MJ, Zhou XP, Talebizadeh Z, Brown M, Takahashi TN, Miles JH, Wang CH, Stratton R, Pilarski R, Eng C (2005) Subset of individuals with autism spectrum disorders and extreme macrocephaly associated with germline PTEN tumour suppressor gene mutations. J Med Genet 42:318-321.

Conn PJ, Pin JP (1997) Pharmacology and functions of metabotropic glutamate receptors. Annu Rev Pharmacol Toxicol 37:205-237.

Dann SG, Selvaraj A, Thomas G (2007) mTOR Complex1-S6K1 signaling: at the crossroads of obesity, diabetes and cancer. Trends Mol Med 13:252-259.

Emamian ES, Hall D, Birnbaum MJ, Karayiorgou M, Gogos JA (2004) Convergent evidence for impaired AKT1-GSK3beta signaling in schizophrenia. Nat Genet 36:131-137.

Endersby R, Baker SJ (2008) PTEN signaling in brain: neuropathology and tumorigenesis. Oncogene 27:5416-5430.

Feng Y, Zhang F, Lokey LK, Chastain JL, Lakkis L, Eberhart D, Warren ST (1995) Translational suppression by trinucleotide repeat expansion at FMR1. Science 268:731-734.

Garber K, Smith KT, Reines D, Warren ST (2006) Transcription, translation and fragile X syndrome. Curr Opin Genet Dev 16:270-275.

Goffin A, Hoefsloot LH, Bosgoed E, Swillen A, Fryns JP (2001) PTEN mu- 
tation in a family with Cowden syndrome and autism. Am J Med Genet 105:521-524.

Greggio E, Singleton A (2007) Kinase signaling pathways as potential targets in the treatment of Parkinson's disease. Expert Rev Proteomics 4:783-792.

Hagerman RJ, Hagerman PJ (2002) The fragile X premutation: into the phenotypic fold. Curr Opin Genet Dev 12:278-283.

Hara K, Maruki Y, Long X, Yoshino K, Oshiro N, Hidayat S, Tokunaga C, Avruch J, Yonezawa K (2002) Raptor, a binding partner of target of rapamycin (TOR), mediates TOR action. Cell 110:177-189.

Hay N, Sonenberg N (2004) Upstream and downstream of mTOR. Genes Dev 18:1926-1945.

Hou L, Klann E (2004) Activation of the phosphoinositide 3-kinase-Aktmammalian target of rapamycin signaling pathway is required for metabotropic glutamate receptor-dependent long-term depression. J Neurosci 24:6352-6361.

Hou L, Antion MD, Hu D, Spencer CM, Paylor R, Klann E (2006) Dynamic translational and proteasomal regulation of fragile $\mathrm{X}$ mental retardation protein controls mGluR-dependent long-term depression. Neuron 51:441-454.

Huber KM, Kayser MS, Bear MF (2000) Role for rapid dendritic protein synthesis in hippocampal mGluR-dependent long-term depression. Science 288:1254-1257.

Huber KM, Gallagher SM, Warren ST, Bear MF (2002) Altered synaptic plasticity in a mouse model of fragile X mental retardation. Proc Natl Acad Sci U S A 99:7746-7750.

Jacquemont S, Hagerman RJ, Hagerman PJ, Leehey MA (2007) Fragile-X syndrome and fragile $\mathrm{X}$-associated tremor/ataxia syndrome: two faces of FMR1. Lancet Neurol 6:45-55.

Jin P, Warren ST (2003) New insights into fragile X syndrome: from molecules to neurobehaviors. Trends Biochem Sci 28:152-158.

Kim DH, Sabatini DM (2004) Raptor and mTOR: subunits of a nutrientsensitive complex. Curr Top Microbiol Immunol 279:259-270.

Kim DH, Sarbassov DD, Ali SM, King JE, Latek RR, Erdjument-Bromage H, Tempst P, Sabatini DM (2002) mTOR interacts with raptor to form a nutrient-sensitive complex that signals to the cell growth machinery. Cell 110:163-175.

Klann E, Dever TE (2004) Biochemical mechanisms for translational regulation in synaptic plasticity. Nat Rev Neurosci 5:931-942.

Leslie NR, Batty IH, Maccario H, Davidson L, Downes CP (2008) Understanding PTEN regulation: PIP2, polarity and protein stability. Oncogene 27:5464-5476.

Loesch DZ, Bui QM, Dissanayake C, Clifford S, Gould E, Bulhak-Paterson D, Tassone F, Taylor AK, Hessl D, Hagerman R, Huggins RM (2007) Molecular and cognitive predictors of the continuum of autistic behaviours in fragile X. Neurosci Biobehav Rev 31:315-326.

Luo J, Manning BD, Cantley LC (2003) Targeting the PI3K-Akt pathway in human cancer: rationale and promise. Cancer Cell 4:257-262.

Miyashiro KY, Beckel-Mitchener A, Purk TP, Becker KG, Barret T, Liu L, Carbonetto S, Weiler IJ, Greenough WT, Eberwine J (2003) RNA cargoes associating with FMRP reveal deficits in cellular functioning in Fmr 1 null mice. Neuron 37:417-431.

Nakanishi S (1994) Metabotropic glutamate receptors: synaptic transmission, modulation, and plasticity. Neuron 13:1031-1037.

Nojima H, Tokunaga C, Eguchi S, Oshiro N, Hidayat S, Yoshino K, Hara K, Tanaka N, Avruch J, Yonezawa K (2003) The mammalian target of rapamycin (mTOR) partner, raptor, binds the mTOR substrates $\mathrm{p} 70$ S6 kinase and $4 \mathrm{E}-\mathrm{BP} 1$ through their TOR signaling (TOS) motif. J Biol Chem 278:15461-15464.

Nosyreva ED, Huber KM (2006) Metabotropic receptor-dependent long- term depression persists in the absence of protein synthesis in the mouse model of fragile X syndrome. J Neurophysiol 95:3291-3295.

O'Donnell WT, Warren ST (2002) A decade of molecular studies of fragile X syndrome. Annu Rev Neurosci 25:315-338.

Oliet SH, Malenka RC, Nicoll RA (1997) Two distinct forms of long-term depression coexist in CA1 hippocampal pyramidal cells. Neuron 18:969-982.

Palmer MJ, Irving AJ, Seabrook GR, Jane DE, Collingridge GL (1997) The group I mGlu receptor agonist DHPG induces a novel form of LTD in the CA1 region of the hippocampus. Neuropharmacology 36:1517-1532.

Penagarikano O, Mulle JG, Warren ST (2007) The pathophysiology of fragile x syndrome. Annu Rev Genomics Hum Genet 8:109-129.

Pin JP, Duvoisin R (1995) The metabotropic glutamate receptors: structure and functions. Neuropharmacology 34:1-26.

Price TJ, Rashid MH, Millecamps M, Sanoja R, Entrena JM, Cervero F (2007) Decreased nociceptive sensitization in mice lacking the fragile $\mathrm{X}$ mental retardation protein: role of mGluR1/5 and mTOR. J Neurosci 27:1395813967.

Ronesi JA, Huber KM (2008) Homer interactions are necessary for metabotropic glutamate receptor-induced long-term depression and translational activation. J Neurosci 28:543-547.

Rong R, Ahn JY, Huang H, Nagata E, Kalman D, Kapp JA, Ty J, Worley PF, Snyder SH, Ye K (2003) PI3K enhancer-Homer complex couples mGluRI to PI3 kinase, preventing neuronal apoptosis. Nat Neurosci 6:1153-1161.

Sabatini DM (2006) mTOR and cancer: insights into a complex relationship. Nat Rev Cancer 6:729-734.

Sarbassov DD, Ali SM, Sabatini DM (2005a) Growing roles for the mTOR pathway. Curr Opin Cell Biol 17:596-603.

Sarbassov DD, Guertin DA, Ali SM, Sabatini DM (2005b) Phosphorylation and regulation of Akt/PKB by the rictor-mTOR complex. Science 307:1098-1101.

Tang SJ, Schuman EM (2002) Protein synthesis in the dendrite. Philos Trans R Soc Lond B Biol Sci 357:521-529.

Tang SJ, Reis G, Kang H, Gingras AC, Sonenberg N, Schuman EM (2002) A rapamycin-sensitive signaling pathway contributes to long-term synaptic plasticity in the hippocampus. Proc Natl Acad Sci U S A 99:467-472.

Waite KA, Eng C (2002) Protean PTEN: form and function. Am J Hum Genet 70:829-844.

Warren S, Sherman SL (2001) The fragile X syndrome. In: The online metabolic and molecular bases of inherited disease (Scriver C, Beaudet A, Valle B, Childs B, Kinzler K, VogelsteinB, eds), pp 1257-1290. New York: McGraw Hill.

Waung MW, Huber KM (2009) Protein translation in synaptic plasticity: mGluR-LTD, Fragile X. Curr Opin Neurobiol 19:319-326.

Weiler IJ, Greenough WT (1993) Metabotropic glutamate receptors trigger postsynaptic protein synthesis. Proc Natl Acad Sci U S A 90:7168-7171.

Weiler IJ, Irwin SA, Klintsova AY, Spencer CM, Brazelton AD, Miyashiro K, Comery TA, Patel B, Eberwine J, Greenough WT (1997) Fragile X mental retardation protein is translated near synapses in response to neurotransmitter activation. Proc Natl Acad Sci U S A 94:5395-5400.

Wiznitzer M (2004) Autism and tuberous sclerosis. J Child Neurol 19:675-679.

Ye K, Hurt KJ, Wu FY, Fang M, Luo HR, Hong JJ, Blackshaw S, Ferris CD, Snyder SH (2000) Pike. A nuclear gtpase that enhances PI3kinase activity and is regulated by protein 4.1N. Cell 103:919-930.

Zhang J, Hou L, Klann E, Nelson DL (2009) Altered hippocampal synaptic plasticity in the FMR1 gene family knockout mouse models. J Neurophysiol 101:2572-2580.

Zori RT, Marsh DJ, Graham GE, Marliss EB, Eng C (1998) Germline PTEN mutation in a family with Cowden syndrome and Bannayan-RileyRuvalcaba syndrome. Am J Med Genet 80:399-402. 